Brazilian Journal

of Chemical

Engineering

ISSN 0104-6632

Printed in Brazil

www.abeq.org.br/bjche

Vol. 36, No. 02, pp. 1007 - 1017, April - June, 2019 dx.doi.org/10.1590/0104-6632.20190362s20180453

\title{
APPLICATION OF RESPONSE SURFACE METHODOLOGY FOR LIPASE CATALYZED SYNTHESIS OF 2-ETHYLHEXYL PALMITATE IN A SOLVENT FREE SYSTEM USING ULTRASOUND
}

\author{
Sarita D. Gawas ${ }^{1}$, Nishat Khan ${ }^{1}$ and Virendra K. Rathod ${ }^{1 *}$ \\ ${ }^{1}$ Institute of Chemical Technology, Department of Chemical Engineering, Mumbai, India. ORCID: 0000-0002-2602-708X; \\ ORCID: 0000-0002-3137-1934; E-mail: vk.rathod@ictmumbai.edu.in - ORCID: 0000-0003-1130-0546
}

(Submitted: October 1, 2018 ; Revised: February 27, 2019 ; Accepted: March 3, 2019)

\begin{abstract}
This study aims at clean production of 2-ethylhexyl palmitate catalyzed by lipase Fermase CALB 10000 in a solvent-free system using ultrasound technology. The central composite design (CCD) of response surface methodology with 4 factors at 3 levels consisting of acid to alcohol molar ratio (1:3-1:7), enzyme loading $(3 \%-7 \%(\mathrm{w} / \mathrm{w}))$, ultrasound power $(60-100 \mathrm{~W})$ and duty cycle $(30 \%-70 \%)$ was used for optimization of the reaction. All the reactions were carried out at a fixed temperature of $60^{\circ} \mathrm{C}, 200 \mathrm{rpm}$ and reaction time $(120$ min). The statistical software, Design-Expert 9.0, was used for regression analysis and graphical analysis of the responses obtained by running the set of designed experiments. The polynomial equation of quadratic order was employed to fit the experimental data. The operating conditions for optimum synthesis of 2-ethylhexyl palmitate were molar ratio of $1: 5.5,5.61 \%(\mathrm{w} / \mathrm{w})$ of the enzyme with ultrasound power $79.54 \mathrm{~W}$ and duty cycle 48.04 $\%$, leading to a reaction conversion as high as $96.56 \%$ in $120 \mathrm{~min}$. The operational stability of the enzyme was maintained at $>70 \%$ conversion up to 5 cycles. Thus, ultrasound is a promising green technology for the lipase catalyzed synthesis of ethylhexyl esters.

Keywords: Ultrasound; Lipase; Esterification; Central composite design; Cosmetics.
\end{abstract}

\section{INTRODUCTION}

2-ethylhexyl palmitate is a fatty acid ester derived from the esterification of 2-ethylhexanol and palmitic acid. It is harmless, clear and a very good skin care agent in cosmetic industries (Richetti et al., 2010a). It is an important organic replacement for silicon and therefore it is widely used in the cosmetic industry for formulations as a solvent, carrying agent, emollient and as a fragrance ingredient (Khan \& Rathod, 2015, Deshmukh \& Rathod, 2017). It also finds wide application in the food, chemical, and pharmaceutical industry. It shows good consumption in polymer and lubricant industry as a plasticizer and solvent respectively (He et al., 2002; Richetti et al., 2010b). The chemical method for synthesis of 2-ethylhexyl palmitate shows a number of drawbacks such as high energy consumption, the formation of many side products and tedious product purification steps. The enzymatic synthesis of ethyl hexyl esters has more significance owing to its greener route of synthesis and these green products are having great demand in the market. These enzymatic syntheses occur at mild operating conditions and provide selective products with great purity (Spinelli et al., 2014; Tan et al., 2006). However, the enzymatic route shows mass transfer barriers when an enzyme in the immobilized form is used which may be overcome by application of ultrasound technology (Sancheti \& Gogate, 2016, Ajmal et al., 2016; De Souza et al., 2017).

Ultrasound radiations cause cavitation in the liquid reaction system, consisting of different steps such as

\footnotetext{
* Corresponding author: Virendra K. Rathod - E-mail: vk.rathod@ictmumbai.edu.in
} 
the formation of bubbles, subsequent growing and breaking of bubbles. The bubble collapse induces high pressure and temperature in the liquid medium, which is responsible for the physical and chemical processes. The intensity of the ultrasound creates shock waves responsible for the effective mixing of different phases and subsequently the rate of reactions increases. The optimum intensity of ultrasound can resolve the problem of mass transfer in enzymatic reactions. However, there are several reports showing the inactivation of enzyme because of the high intensity of ultrasound. Therefore, the study of optimum frequency and ultrasound intensity is essential for enzymatic reaction (Rokhina et al., 2009, Gogate \& Kabadi, 2009; Bansode \& Rathod, 2017). Ultrasound radiations enhance the diffusion of reactants into the enzymes as well as renew the interface by jets formed during cavitation. It also reduces the transportation barrier so that the enzyme reaches its target site and gives higher conversion in a smaller time span. It also prevents agglomeration of enzymes, which eventually improves enzyme stability. Ultrasound technology can drastically improve the rate of reaction and reduce the duration of reaction (Waghmare \& Rathod, 2016).

The traditional method used for optimization of enzymatic reactions varies only one factor at a time, keeping all other factors constant. This does not give a proper idea about the interaction of various parameters amongst each other. Response surface methodology (RSM) and central composite design (CCD) on the other hand enable one to elucidate the response or conversion by using various combinations of process parameters. This method brings about proper optimization of the reaction under study (Bezerra et al., 2008; Khan et al., 2016).

Here, synthesis of 2-ethylhexyl palmitate was carried out by using Fermase CALB 10000, a commercial immobilized Candida antarctica lipase B in solvent free condition. The central composite design (CCD) of response surface methodology with 4 factors at 3 levels; consisting of acid to alcohol molar ratio, enzyme loading, ultrasound power, and duty cycle was used for optimization of reaction. The reusability of Fermase CALB 10000 under optimum reaction conditions was analyzed up to 5 cycles.

\section{MATERIALS AND METHODS}

\section{Materials}

2-Ethylhexanol and palmitic acid were purchased from Sigma-Aldrich, Mumbai, India. Fermase CALB 10000 a commercial lipase from Candida Antarctica B immobilized on a macroporous polyacrylate resin was kindly donated by Fermenta Biotech Ltd., Mumbai (India). The activity of the enzyme was reported as $10000 \mathrm{PLU} / \mathrm{g}$. Methanol was purchased from S.D. Fine
Chemical, Mumbai, India. Phenolphthalein, $\mathrm{NaOH}$, ethanol, and potassium hydroxide were procured from Thomas Baker (Chemicals) Pvt. Ltd., Mumbai. All chemicals were analytical grade and used without purification.

\section{Ultrasound assisted esterification reaction}

The esterification reaction of 2-ethyl hexanol with palmitic acid was carried out in a $50 \mathrm{~mL}$ glass baffled reactor with 4 turbine glass impeller. The glass reactor was placed at a height of $2 \mathrm{~cm}$ from the base of an ultrasound water bath as reported in earlier work (Kulkarni \& Rathod, 2014). The ultrasound bath consists of 4 transducers having a frequency of $25 \mathrm{kHz}$ with maximum power input of $200 \mathrm{~W}$. The temperature of the bath was maintained at $60^{\circ} \mathrm{C}$ and reaction is studied in a solvent free system (SFS). The lipase was added into the homogeneous reaction mixture to initiate the reaction and the speed of agitation was kept at 200 RPM. The reaction samples were withdrawn periodically and titrated against 0.025 $\mathrm{N} \mathrm{KOH}$ to determine the acid value. The percentage conversion was further calculated from the acid value. The various parameters like molar ratio (acid: alcohol), enzyme loading, ultrasound power and duty cycle were optimized by using central composite design (CCD) and response surface methodology (RSM).

\section{Titrimetric analysis}

The analysis of the samples was done by titrimetric analysis. The acid value of the reaction was obtained by titrating it with $0.025 \mathrm{M} \mathrm{KOH}$ solution using phenolphthalein as an indicator and ethanol as a quenching agent. The acid value was calculated by using the following equation (Bucalá et al., 2006)

Acid value $=\frac{56.1 \times \text { Normality of } \mathrm{KOH}(\mathrm{M}) \times \mathrm{B}(\mathrm{mL})}{\text { Weight of sample }(\mathrm{g})}$

where $\mathrm{B}$ is the burette reading in $\mathrm{mL}$. The conversion (\%) of reacted acid was determined from the acid values obtained for the initial sample and final samples.

\section{NMR analysis}

For the evaluation by the ${ }^{1} \mathrm{H}$ NMR method, the product was purified by simple distillation. The reaction mixture was filtered through Whatman paper to remove the immobilized enzyme. The unreacted palmitic acid in the reaction mixture was neutralized with $\mathrm{Na}_{2} \mathrm{CO}_{3}$ and the traces of formed salt removed by several water washings. Anhydrous $\mathrm{MgSO}_{4}$ was added to the remaining mixture as a drying agent to remove the water from the mixture. The residual 2-ethylhexanol was removed by distillation. The chemical structure of the purified 2-ethylhexyl palmitate was authenticated by ${ }^{1} \mathrm{H}$ NMR analysis in $\mathrm{CDCl}_{3}$ using an Agilent 
Technology MR400 spectrometer. The NMR spectra were recorded in deuterated chloroform by using tetramethylsilane as an internal standard. The relative areas of the signals were obtained by electronic integration and the chemical shifts $(\delta)$ are expressed in ppm relative to the standard signal and the multiplicities ( $\mathrm{s}=$ singlet, $\mathrm{t}=$ triplet, and $\mathrm{m}=$ multiplet) and coupling constants $(\mathrm{J})$ in $\mathrm{Hz}$ were calculated.

\section{Evaluation of physicochemical properties}

The properties of 2-EHP were tested using standard methods, namely acid number: AOCS, 2009; density: ASTM, 2016a; kinematic viscosity: ASTM, 2017a; moisture content: ASTM, 2016b; pour point: ASTM, 2017b; Refractive index: A.O.C.S. Official Method Tp 1a-64.

\section{Design of experiment for RSM}

A 4 factor 3 level experimental design was considered for the synthesis of 2-ethyl hexyl palmitate, leading to a set of 30 experiments. The variables and their levels for the synthesis of 2-ethylhexyl palmitate, i.e., molar ratio (1:3 - 1:7), enzyme loading (3$7 \%(\mathrm{w} / \mathrm{w}))$, ultrasound power $(60-100 \mathrm{~W})$ and duty cycle (30-70\%), were obtained based on preliminary experiments. The four variables and their levels are shown in Table 1. The design expert 9.0 version was used to determine the regression and for graphical analysis of the obtained data. The second-order polynomial equation for the variables was as follows (Bezerra et al., 2008; Martins et al., 2013):

$$
Y=\beta_{0}+\sum_{i=1}^{n} \beta_{i} X_{i}+\sum_{i=1}^{n} \beta_{i i} X_{i}^{2}+\sum_{i=1}^{n-1} \sum_{j=i+1}^{n} \beta_{i j} X_{i} X_{j}
$$

where $\mathrm{Y}$ is the conversion (\%), $\beta_{0}$ the constant, $\beta_{\mathrm{i}}$ the coefficients for the linear, $\beta_{\mathrm{ii}}$ coefficients for the quadratic, and $\beta_{\mathrm{if}}$ for the interaction effects. The $X_{\mathrm{i}}$ and $\mathrm{X}_{\mathrm{j}}$ are the coded level of variables $\mathrm{xi}$ and $\mathrm{x}_{\mathrm{j}}$. The design expert 9.0 was used to determine the surfaces plot for variables using the above equation.

Table 1. The variables and their experimental design levels.

\begin{tabular}{cccc}
\hline \multirow{2}{*}{ Variable } & \multicolumn{3}{c}{ Levels } \\
\cline { 2 - 4 } & $\mathbf{- 1}$ & $\mathbf{0}$ & $\mathbf{+ 1}$ \\
\hline Molar ratio acid:alcohol (A) & $1: 3$ & $1: 5$ & $1: 7$ \\
Enzyme loading (\%) (B) & 3 & 5 & 7 \\
Power (W) (C) & 60 & 80 & 100 \\
Duty cycle (\%) (D) & 30 & 50 & 70 \\
\hline
\end{tabular}

\section{Enzyme reusability}

The reactions were carried out at optimized conditions obtained by RSM. At the end of the reaction, the lipase was filtered and washed with acetone to remove traces of substrate or products. The washed lipase was dried at $40^{\circ} \mathrm{C}$ and introduced into a fresh reaction mixture (Gharat \& Rathod, 2013). The five successive cycles of the reaction were carried out for the reusability study.

\section{Scanning electron microscopy (SEM)}

The morphology of untreated enzyme and ultrasound assisted irradiated immobilised enzyme after reusability cycles was examined by scanning electron microscopy with a JEOL-JSM 6380 LA instrument. The analysis of the Fermase CALB 10000 enzyme was performed before and after the ultrasonic irradiation.

\section{RESULTS AND DISCUSSION}

\section{Effect of reaction time}

The effect of reaction time on the esterification of 2-ethyl hexanol and palmitic acid by Fermase CALB 10000 was carried out in an ultrasound bath and results are depicted in Figure 1. It is observed that the percentage conversion of 2-ethylhexyl palmitate increased to $94.39 \%$ with an increase in time up to $120 \mathrm{~min}$. As the reaction proceeds further, a marginal change in percentage conversion was detected after $120 \mathrm{~min}$. Therefore, $120 \mathrm{~min}$ was considered as an optimum reaction time for further reactions. In previous literature, Richetti et al. (2010b) reported $6 \mathrm{~h}$ reaction time for the synthesis of 2-ethylhexyl palmitate with Novozym 435 in conventional synthesis. However, in the present study, the application of low-intensity ultrasound may reduce the reaction time to $120 \mathrm{~min}$. This indicated that ultrasound may deliver better mixing of substrate solution which increased the interaction between the substrate and enzyme.

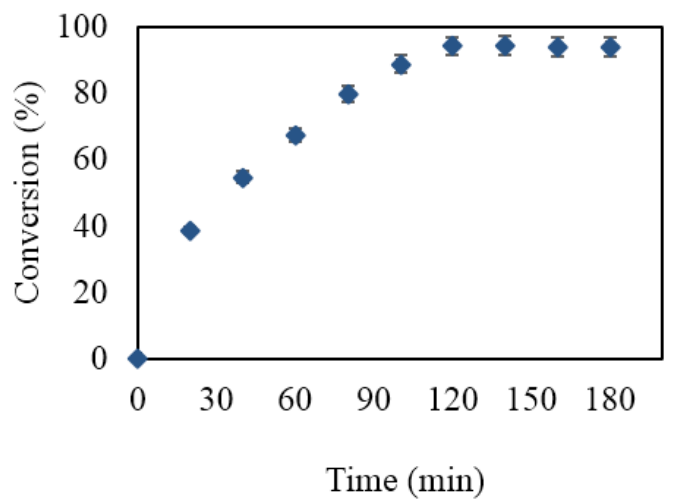

Figure 1. Time course for lipase-catalyzed synthesis of 2-ethylhexyl palmitate in SFS. [Reaction conditionsPalmitic acid: 2-ethyl hexyl alcohol = 1:5, Temperature $=60^{\circ} \mathrm{C}$, Enzyme loading $=5 \%(\mathrm{w} / \mathrm{w}$ of substrates $)$, Speed of agitation $=200 \mathrm{rpm}$, Frequency $=25 \mathrm{kHz}$, Power $=80 \mathrm{~W}$, Duty cycle $=50 \%]$.

\section{Model fitting and analysis of variance (ANOVA)}

RSM is an empirical statistical technique used to obtain statistically acceptable results from a lower 
number of experimental runs. It is an excellent technique for the optimization of the process, appraising the effect of multiple parameters around reaction variables (Melo et al., 2005). Table 2 shows the designed experiments and the actual and predicted results for ultrasound assisted 2-ethylhexyl palmitate (2-EHP) synthesis for $120 \mathrm{~min}$ of reaction by using Fermase CALB 10000 as a biocatalyst. The other parameters such as $60^{\circ} \mathrm{C}$ temperature, $200 \mathrm{rpm}$ speed and $25 \mathrm{kHz}$ frequency of ultrasound were kept constant in all the runs of the experimental design. The response surface regression method was used to fit to a second-order polynomial quadratic equation and Eq. (2) is given below:

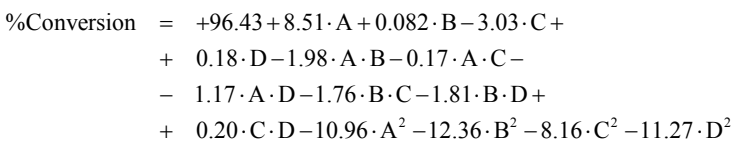

where A, B, C and D are the coded values of molar ratio, enzyme loading, ultrasound power, and duty cycle, respectively.

Table 3 shows the analysis of variance (ANOVA) for the model. The ANOVA specifies that the second-order polynomial model was highly noteworthy with very low P-value $<0.0001$ and the F-value (779.36). The value of $\mathrm{R}^{2}$ (coefficient of determination) determines the overall performance of the model. The high value of $\mathrm{R}^{2}(0.99)$ and $\mathrm{R}^{2}$ with adjustment, $\mathrm{R}^{2}$ adj $(0.99)$, close to 1 indicates the significance of the model (Chang et al., 2005; Kapucu et al., 2003). This represents the close correlation between theoretical and predicted values. The results revealed that the molar ratio (A), enzyme loading (B) and ultrasound power were the most significant factors with a low p-value $(<0.0001)$ applying the effect on the conversion (\%) of 2-EHP. The ultrasound duty cycle is not significant for 2-EHP conversion. The interaction terms $(\mathrm{AB}, \mathrm{BC}, \mathrm{BD})$ and the quadratic terms $\left(\mathrm{A}^{2}, \mathrm{~B}^{2}, \mathrm{C}^{2}, \mathrm{D}^{2}\right)$ are significant. However, the interaction terms (AC, AD, CD) are not significant. Figure 2 illustrates the experimental values of conversion (\%) versus those predicted by the model and the linearity shows the good fit of the model.

Among different runs, the highest conversion (96.87\%) was obtained in run no. 28 (1:5 acid:alcohol, $5 \%$ enzyme loading, $80 \mathrm{~W}$ power and $50 \%$ duty cycle) and the lowest conversion $(61.36 \%)$ in run no. $16(1: 3$ acid:alcohol, 3\% enzyme loading, $80 \mathrm{~W}$ power, $50 \%$ duty cycle). These outcomes are different than reported

Table 2. Central composite rotatable second-order design, experimental data, and predicted values for 4-factor-5level response surface analysis.

\begin{tabular}{|c|c|c|c|c|c|c|}
\hline $\begin{array}{l}\text { RUN } \\
\text { NO. }\end{array}$ & $\begin{array}{c}\text { Molar ratio } \\
\text { (acid:alcohol) } \\
\text { A (mol/mol) } \\
\end{array}$ & $\begin{array}{c}\text { Enzyme } \\
\text { loading } \\
\text { B (\%) } \\
\end{array}$ & $\begin{array}{c}\text { Ultrasound } \\
\text { power } \\
\text { C (watt) } \\
\end{array}$ & $\begin{array}{c}\text { Duty cycle } \\
\text { D (\%) }\end{array}$ & $\begin{array}{l}\text { \% Conversion } \\
\text { (Experimental) }\end{array}$ & $\begin{array}{l}\text { \%Conversion } \\
\text { (Predicted) }\end{array}$ \\
\hline 1 & 3.00 & 7.00 & 80.00 & 50.00 & 67.41 & 67.40 \\
\hline 2 & 5.00 & 7.00 & 60.00 & 50.00 & 81.28 & 81.52 \\
\hline 3 & 5.00 & 5.00 & 60.00 & 70.00 & 79.69 & 80.01 \\
\hline 4 & 5.00 & 3.00 & 100.00 & 50.00 & 74.23 & 73.82 \\
\hline 5 & 5.00 & 5.00 & 80.00 & 50.00 & 96.52 & 96.48 \\
\hline 6 & 3.00 & 5.00 & 80.00 & 30.00 & 64.87 & 65.93 \\
\hline 7 & 5.00 & 5.00 & 80.00 & 50.00 & 95.98 & 96.42 \\
\hline 8 & 3.00 & 5.00 & 100.00 & 50.00 & 65.87 & 65.93 \\
\hline 9 & 5.00 & 5.00 & 80.00 & 50.00 & 96.58 & 96.42 \\
\hline 10 & 7.00 & 5.00 & 100.00 & 50.00 & 83.24 & 82.63 \\
\hline 11 & 5.00 & 5.00 & 60.00 & 30.00 & 80.35 & 80.02 \\
\hline 12 & 7.00 & 7.00 & 80.00 & 50.00 & 80.36 & 80.47 \\
\hline 13 & 5.00 & 5.00 & 100.00 & 30.00 & 73.35 & 73.58 \\
\hline 14 & 5.00 & 3.00 & 80.00 & 30.00 & 69.78 & 69.97 \\
\hline 15 & 7.00 & 5.00 & 80.00 & 30.00 & 83.68 & 83.70 \\
\hline 16 & 3.00 & 3.00 & 80.00 & 50.00 & 61.36 & 61.79 \\
\hline 17 & 3.00 & 5.00 & 80.00 & 70.00 & 67.22 & 67.03 \\
\hline 18 & 5.00 & 5.00 & 80.00 & 50.00 & 96.35 & 96.48 \\
\hline 19 & 3.00 & 5.00 & 60.00 & 50.00 & 71.44 & 71.65 \\
\hline 20 & 5.00 & 5.00 & 100.0 & 70.00 & 73.47 & 74.34 \\
\hline 21 & 7.00 & 5.00 & 80.00 & 70.00 & 81.35 & 81.72 \\
\hline 22 & 5.00 & 7.00 & 100.00 & 50.00 & 72.11 & 71.94 \\
\hline 23 & 5.00 & 5.00 & 80.00 & 50.00 & 96.27 & 96.42 \\
\hline 24 & 5.00 & 7.00 & 80.00 & 30.00 & 74.85 & 75.25 \\
\hline 25 & 7.00 & 5.00 & 60.00 & 50.00 & 89.48 & 89.02 \\
\hline 26 & 5.00 & 3.00 & 60.00 & 50.00 & 76.35 & 76.35 \\
\hline 27 & 5.00 & 7.00 & 80.00 & 70.00 & 72.58 & 71.99 \\
\hline 28 & 5.00 & 5.00 & 80.00 & 50.00 & 96.87 & 96.42 \\
\hline 29 & 7.00 & 3.00 & 80.00 & 50.00 & 82.23 & 82.79 \\
\hline 30 & 5.00 & 3.00 & 80.00 & 70.00 & 74.77 & 73.97 \\
\hline
\end{tabular}


Table 3. Analysis of variance (ANOVA) for Response Surface Quadratic Model.

\begin{tabular}{cccccc}
\hline Source & $\begin{array}{c}\text { Sum } \\
\text { of squares }\end{array}$ & Df & $\begin{array}{c}\text { Mean } \\
\text { square }\end{array}$ & F-value & $\begin{array}{c}\text { P-value } \\
\text { Prob }>\text { F }\end{array}$ \\
\hline Model & 3305.07 & 14 & 236.08 & 779.36 & $<0.0001$ significant \\
A-MR & 870.06 & 1 & 870.06 & 2872.34 & $<0.0001$ \\
B-Enzyme & 8.13 & 1 & 8.13 & 26.85 & $<0.0001$ \\
C-Power & 109.93 & 1 & 109.93 & 362.91 & 0.0001 \\
D-Duty cycle & 0.40 & 1 & 0.40 & 1.33 & $<0.0001$ \\
AB & 15.72 & 1 & 15.72 & 51.90 & 0.5518 \\
AC & 0.11 & 1 & 0.11 & 0.37 & $<.0007$ \\
AD & 5.48 & 1 & 5.48 & 18.08 & $<0.0001$ \\
BC & 12.43 & 1 & 12.43 & 41.02 & 0.48901 \\
BD & 13.18 & 1 & 13.18 & 43.50 & $<0.0001$ \\
CD & 0.15 & 1 & 0.15 & 0.50 & $<0.0001$ \\
A2 & 823.13 & 1 & 823.13 & 2717.39 & $<0.0001$ \\
B2 & 1046.93 & 1 & 1046.93 & 3456.22 & $<0.0001$ \\
C2 & 456.73 & 1 & 456.73 & 1507.79 & 2877.17 \\
D2 & 871.53 & 1 & 871.53 & & 0.0565 Not significant \\
Residual & 4.54 & 15 & 0.30 & & \\
\hline Lack of Fit & 4.08 & 10 & 0.41 & 4.45 & \\
\hline Pure Error & 0.46 & 5 & 0.092 & & \\
Cor Total & 3309.62 & 29 & & & \\
\hline
\end{tabular}

Design-Expert ${ }^{\circledR}$ Softw are
$\%$ conversion
Color points by value of
$\%$ conversion:
$\square 6.87$
61.35

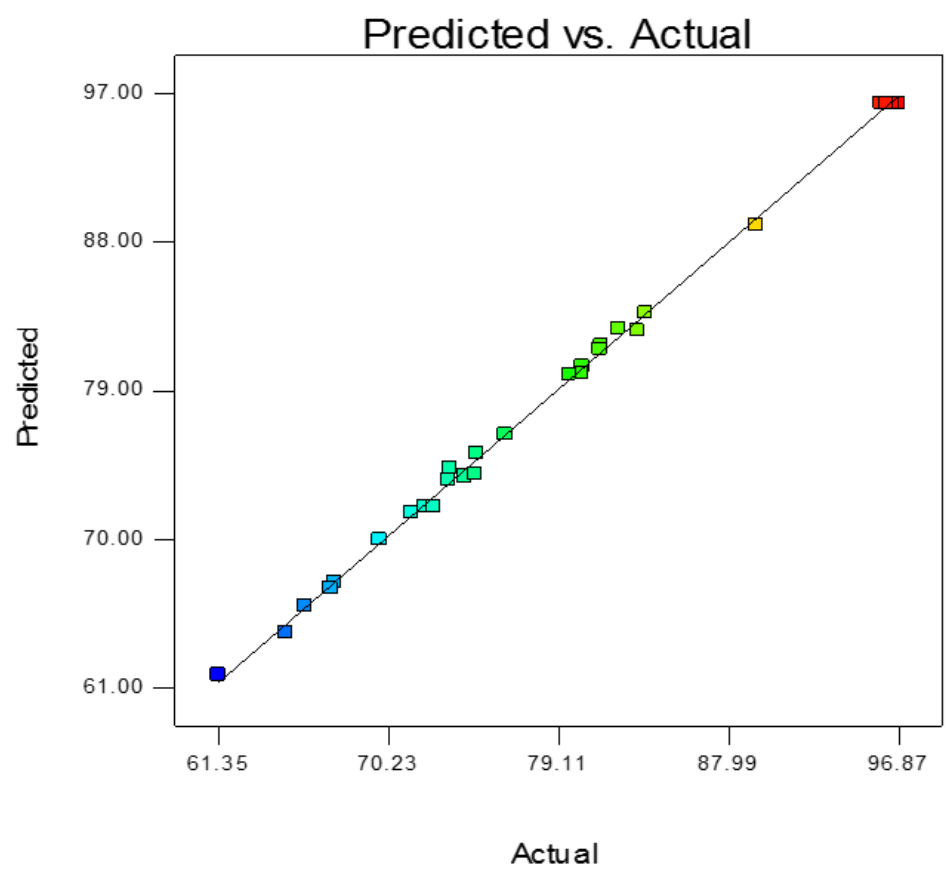

Figure 2. Correlation of actual conversion yields and values predicted by the response surface model.

in previous literature (Richetti et al., 2010a; Richetti et al., 2010b), where Novozym 435 and Lipozyme RM IM were used as biocatalyst with standard mechanical stirring. Richetti et al. (2010b) revealed that for $93 \%$ conversion of 2-EHP, the optimized conditions were: palmitic acid:2-ethyl hexanol ratio; 1:5.5, 70 ${ }^{\circ} \mathrm{C}$ temperature, 10.5 wt.\% enzyme concentration, $150 \mathrm{rpm}$ speed of agitation and $6 \mathrm{~h}$ reaction time. In the presence of Lipozyme RM IM as a catalyst, the optimum conditions for the synthesis of 2-EHP were: palmitic acid:2-ethylhexanol ratio 1:3, temperature $70^{\circ} \mathrm{C}$, enzyme loading $10 \mathrm{wt} \%, 150 \mathrm{rpm}$, giving $95.22 \%$ conversion in $6 \mathrm{~h}$ (Richetti et al., 2010a). In the present study, the optimization process confirmed that ultrasound irradiation intensifies the process by reducing the amount of enzyme and reaction time along with higher percentage conversion.

\section{Mutual effect of parameters}

The response surface plot provides the variation of percentage conversion of 2-ethylhexyl palmitate (2-EHP) with independent variables and is shown in Figure 3-8. Each 3D surface signifies a limitless combination of two variables by keeping the other two variables at their zero levels. Figure 3 shows the 3D surface plot for 2-EHP conversion versus molar ratio 


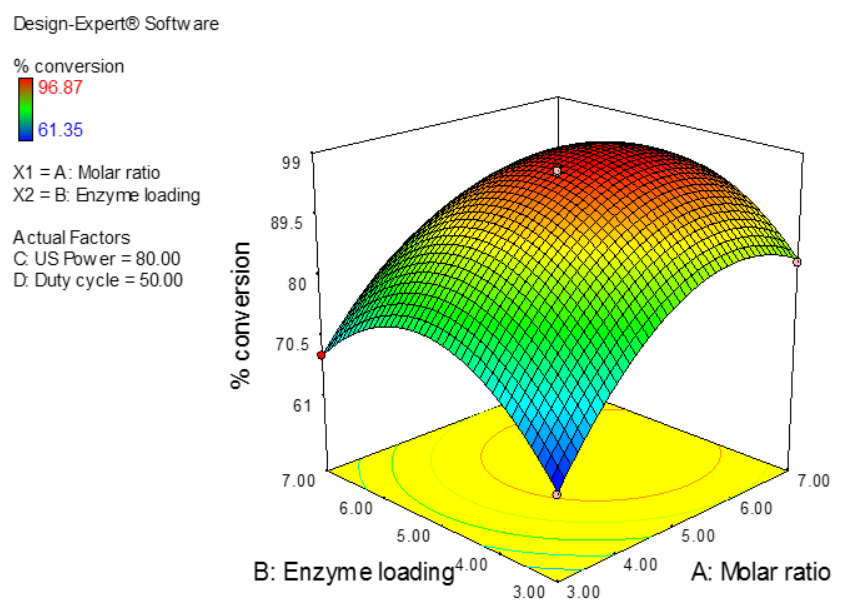

Figure 3. Mutual effect of the enzyme loading and the molar ratio on the \% conversion keeping constant US power $80 \mathrm{~W}$ and duty cycle $50 \%$.

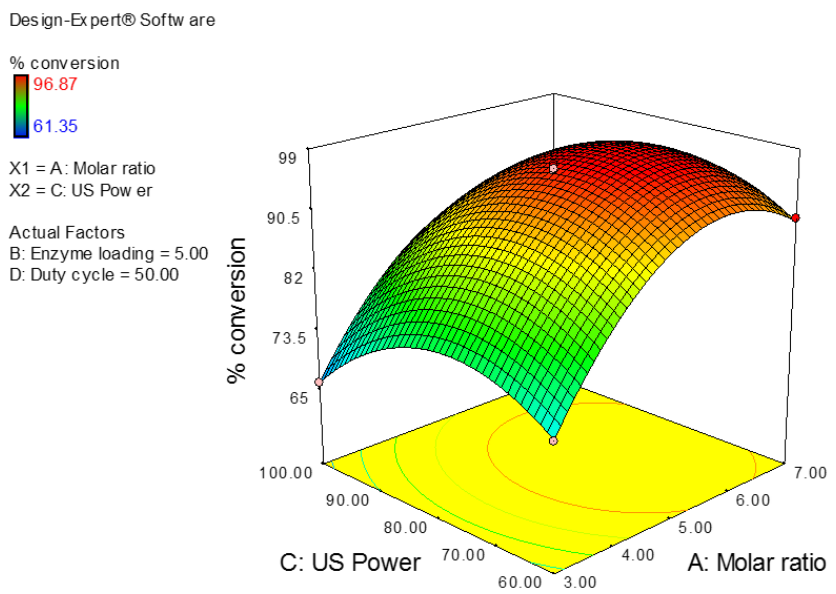

Figure 4. Mutual effect of the ultrasound power and the molar ratio on the \% conversion keeping constant enzyme loading $5 \%(\mathrm{w} / \mathrm{w})$ and Duty cycle $50 \%$.

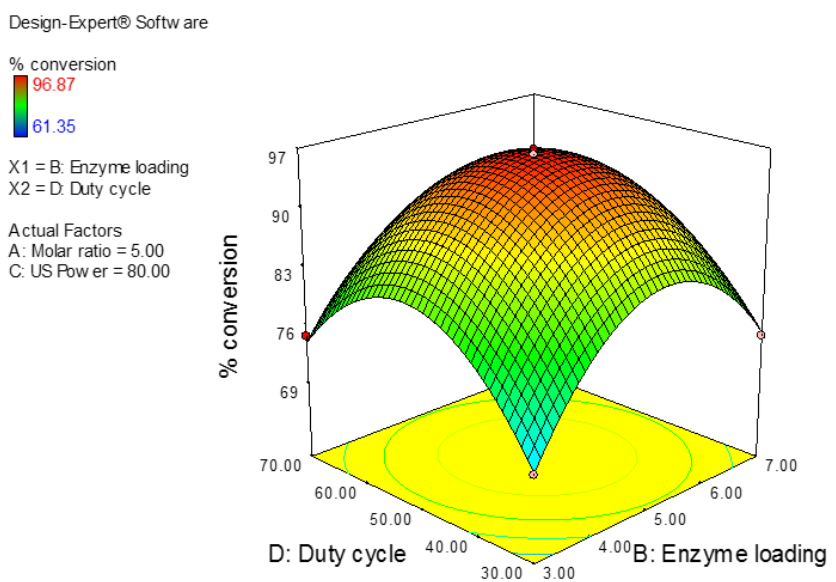

Figure 5. Mutual effect of the duty cycle and the enzyme loading on the $\%$ conversion keeping constant US power $80 \mathrm{~W}$ and molar ratio 1:5.

of palmitic acid to 2-ethylhexyl alcohol and enzyme loading when ultrasound power $(80 \mathrm{~W})$ and duty cycle $(50 \%)$ were kept at zero levels. The conversion

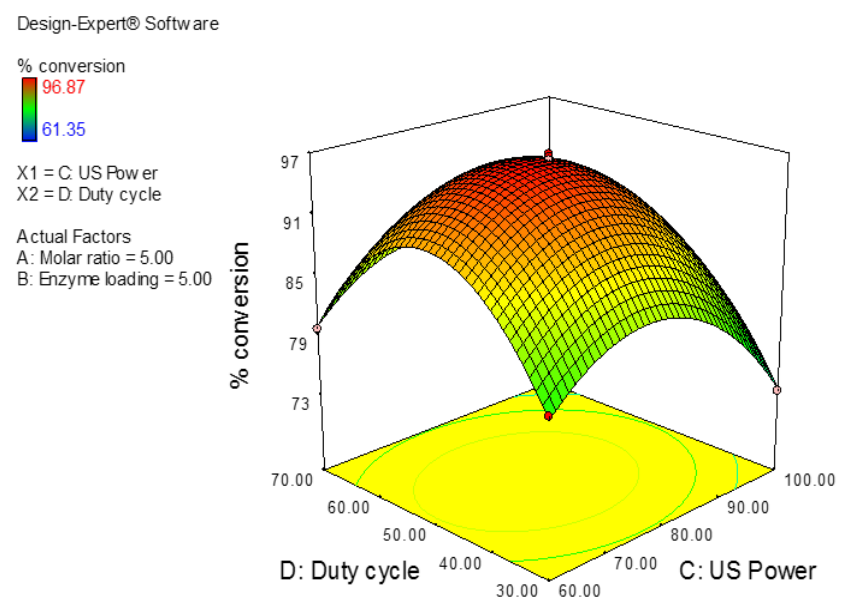

Figure 6. Mutual effect of the duty cycle and the US power on the $\%$ conversion keeping constant molar ratio (1:5) and enzyme loading $5 \%(\mathrm{w} / \mathrm{w})$.

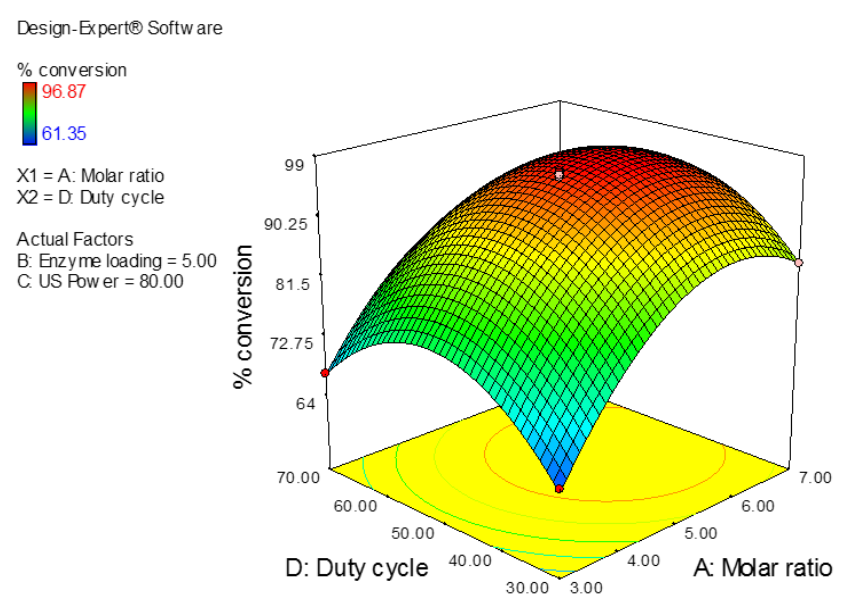

Figure 7. Mutual effect of the duty cycle and the molar ratio on the \% conversion keeping constant enzyme loading $5 \%(\mathrm{w} / \mathrm{w})$ and US power $80 \mathrm{~W}$.

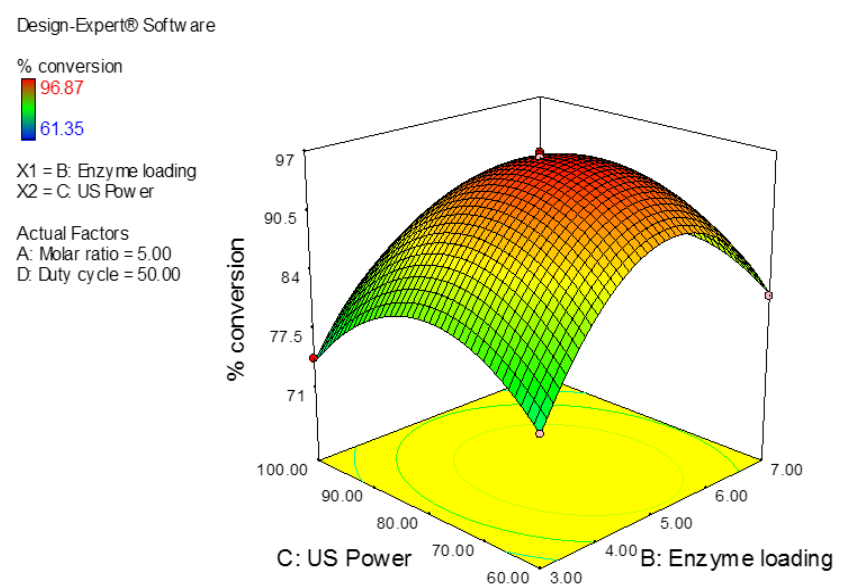

Figure 8. Mutual effect of the enzyme loading and US power on the $\%$ conversion keeping constant molar ratio (1:5) and duty cycle $50 \%$.

was increased up to $96 \%$ with an increase in molar ratio and enzyme loading from 1:3 to $1: 5$ and $3 \%$ to $5 \%(\mathrm{w} / \mathrm{w})$ respectively. The esterification reaction 
is reversible in nature and required excess alcohol to favor the forward reaction for cosmetic emollient. It can be observed that there is a decrease in the reaction conversion by changing the molar ratio from 1:5 to 1:7. However, an excess of alcohol may denature the enzyme activity and reduce the conversion (Gawas $\&$ Rathod, 2018). Figure 4 represents the response surface plot for percentage conversion of 2-EHP as a function of ultrasound (US) power and the molar ratio at a fixed enzyme loading $5 \%(\mathrm{w} / \mathrm{w})$ and duty cycle $50 \%$. It can be observed that, as the molar ratio and ultrasound power increase from 1:3-1:5 and $60 \mathrm{~W}-80$ $\mathrm{W}$, respectively, a significant increase in conversion was observed. When ultrasound power increases from $60 \mathrm{~W}$ to $80 \mathrm{~W}$, the cavitation enhances in the reaction mixture which decreases the mass transfer barrier between the reactants. Alternatively, enzyme-substrate complex increases and also the conversion of the ester (Subhedar \& Gogate, 2016). Above a 1:5 molar ratio and $80 \mathrm{~W}$, conversion did not increase quickly. This may be due to an excess of alcohol beyond the limit that may inhibit the activity of the enzyme. The high ultrasound power may damage the structure of the enzyme, which leads to a decrease in conversion (Badgujar et al., 2016). Figure 5 shows the mutual effect of the duty cycle and the enzyme loading on the $\%$ conversion keeping other parameters at their centre values. It is observed that an increase in duty cycle from $30 \%$ to $50 \%$ and enzyme loading from $3 \%$ to $5 \%$ may enhance the conversion up to $96 \%$ due to an increasing number of catalytic active sites which accelerates the reaction towards the forward direction (Zhang et al., 2016). Up to $50 \%$ duty cycle, the conversion reached the maximum level and beyond this conversion decreased. The optimum ultrasound irradiation may enhance the reactivity of immobilized enzyme which alters the rate of conversion (Waghmare \& Rathod, 2016). Figure 6 depicts the effect of US power and duty cycle on the conversion of 2-ethylhexyl palmitate when the molar ratio and enzyme loading were held at zero. The most favourable duty cycle appeared to be $50 \%$ (10 min ON and $10 \mathrm{~min}$ OFF of ultrasound irradiation time). With an increase in duty cycle and ultrasound frequency, the conversion increases due to cavitation phenomena. Cavitational impacts might be influenced unfavourably at the higher power level.
The high ultrasound power and duty cycle decrease the percentage conversion, which is attributed to the inactivation of lipase due to excess of ultrasound waves (Bansode \& Rathod, 2017). Figure 7 shows the interaction between molar ratio and duty cycle by keeping other factors at their centre values. The minimum molar ratio (1:3) and duty cycle (30\%) give minimum conversion $(61 \%)$, while the increase in ratio to $1: 5$ with $50 \%$ duty cycle produces maximum conversion (96\%). Upon increasing the duty cycle to $70 \%$, the conversion was decreased to $68 \%$; this is attributed to the inactivation of the enzyme due to excess irradiation (Khan et al., 2018). The interactive effect between US power and enzyme loading was shown in Figure 8. In the beginning, the conversion increases sharply as power increases from $60 \mathrm{~W}$ to 80 $\mathrm{W}$, while with an increase in enzyme loading and when the power exceeded $80 \mathrm{~W}$, the conversion decreases. The optimum ultrasound irradiation may enhance the rate of reaction, but an excess of ultrasound power may inactivate the enzyme or reduce the activity of the enzyme (Khan et al., 2016). Table 4 shows the comparative results of conventional and ultrasound assisted synthesis for 2-ethylhexyl palmitate. The conventional synthesis (Richetti et al., 2010b) reported earlier showed higher enzyme loading, longer reaction time with low conversion for 2-ethyl hexyl palmitate (Table 4). The present work reveals the significance of ultrasound technology for optimal and improved reaction conditions with the help of RSM. All variables were studied at the same time by central composite design, to identify their best combinations and their interactions.

\section{Optimum conditions and validation of the model}

The optimum parameters for Fermase CALB 10000 catalyzed synthesis of 2-ethylhexyl palmitate were determined using design expert 9.0 software. The acceptability of the model was examined by another independent condition given by ridge max analysis. The optimal conditions for maximum conversion were obtained at 1:5.5 substrate molar ratio of palmitic acid to 2-ethyl hexanol; $5.61 \%(\mathrm{w} / \mathrm{w})$ molar ratio, 79.54 $\mathrm{W}$ ultrasound power and $48.04 \%$ duty cycle at $60^{\circ} \mathrm{C}$ in 120 min of reaction. At these optimum conditions, experiments were conducted in triplicate to verify

Table 4. Comparison between the present study with literature for the synthesis of ethyl hexyl palmitate.

\begin{tabular}{ccc}
\hline Parameters & $\begin{array}{c}\text { Ultrasound synthesis } \\
\mathbf{( 7 9 . 5 4} \mathbf{~ W 8 . 0 4} \% \text { Duty cycle) } \\
\text { Present work }\end{array}$ & $\begin{array}{c}\text { Conventional Synthesis } \\
\text { Richetti et al. (2010) }\end{array}$ \\
\hline Molar ratio/Solvent & $1: 5.5 / *$ SFS & $1: 5.5 / *$ SFS \\
Enzyme loading $(w t \%)$ & Novozym 5.61 & Novozym 10.5 \\
Temperature $\left({ }^{\circ} \mathrm{C}\right)$ & 60 & 70 \\
Time $(\min )$ & 120 & 360 \\
Conversion $(\%)$ & 96.56 & 93 \\
\hline
\end{tabular}

*SFS- solvent free system. 
predicted values for $120 \mathrm{~min}$. The experimental average conversion was $96.56 \%$, while predicted conversion was $96.86 \%$, showing the validation of the model.

\section{Confirmation of product formation by ${ }^{1} \mathrm{H}$ NMR}

Figure 9 shows the 2-ethylhexyl palmitate ${ }^{1} \mathrm{H}$ NMR spectrum in $\mathrm{CDCl}_{3}$. The NMR spectrum confirmed the 2-ethylhexyl palmitate synthesis and the chemical shifts $(\delta)$ of the ${ }^{1} \mathrm{H}$ NMR $\left(400 \mathrm{MHz}, \mathrm{CDCl}_{3}, \mathrm{TMS}\right)$ spectrum are as follows: $3.97(\mathrm{~s}, 2 \mathrm{H}), 2.28(\mathrm{~d}, 2 \mathrm{H})$, $2.15(\mathrm{~s}, 1 \mathrm{H}), 1.59$ (s, 4H), 1.53-1.16 (m, $30 \mathrm{H}), 0.87$ (s, 9H).

\section{Physicochemical evaluation of 2-EHP}

The emollient properties of 2-EHP were studied and the observed results are listed in Table 5. The acid value of 2-EHP was only $0.62 \mathrm{mg} \mathrm{KOH} \mathrm{g}^{-1}$ indicating the low corrosive effect. The kinematic viscosity of 2-EHP was $8.39 \mathrm{~mm}^{2} \mathrm{~s}^{-1}$ at $40{ }^{\circ} \mathrm{C}$, suggesting good spreadability. The moisture content of 2-EHP was 0.54 wt $\%$, which met the requirement for an emollient. Pour point is an important factor for the application of ester at low temperatures. The pour point of 2-EHP
Table 5. Physicochemical evaluation of 2-EHP.

\begin{tabular}{cc}
\hline Property & 2-EHP \\
\hline Acid value $\left(\mathrm{mg} \mathrm{KOH} \mathrm{g}^{-1}\right)$ & 0.62 \\
Density at $25^{\circ} \mathrm{C}\left(\mathrm{gcm}^{-3}\right)$ & 854.2 \\
Kinematic viscosity at $40^{\circ} \mathrm{C}\left(\mathrm{mm}^{2} \mathrm{~s}^{-1}\right)$ & 8.39 \\
Moisture content $(\mathrm{wt} . \%)$ & 0.54 \\
Pour point $\left({ }^{\circ} \mathrm{C}\right)$ & -3.5 \\
Refractive index & 1.45 \\
\hline
\end{tabular}

was determined to be $-3.5^{\circ} \mathrm{C}$, which was significantly low. The refractive index of 1.45 indicates good luster imparting properties.

\section{Reusability of enzyme}

The reusability study is very important because it significantly reduces the process cost and accelerates the industrial application. The reusability of Fermase CALB 10000 was detected by conducting 5 cycles of reactions under optimized process parameter conditions. After each cycle, the enzyme was treated as described in section 2.5. The same steps were followed after each cycle and treated enzyme used in the fresh reaction. Figure 10 shows a decrease in the conversion from $96.56 \%$ to $84.13 \%$ after five successive cycles under ultrasound irradiations. The

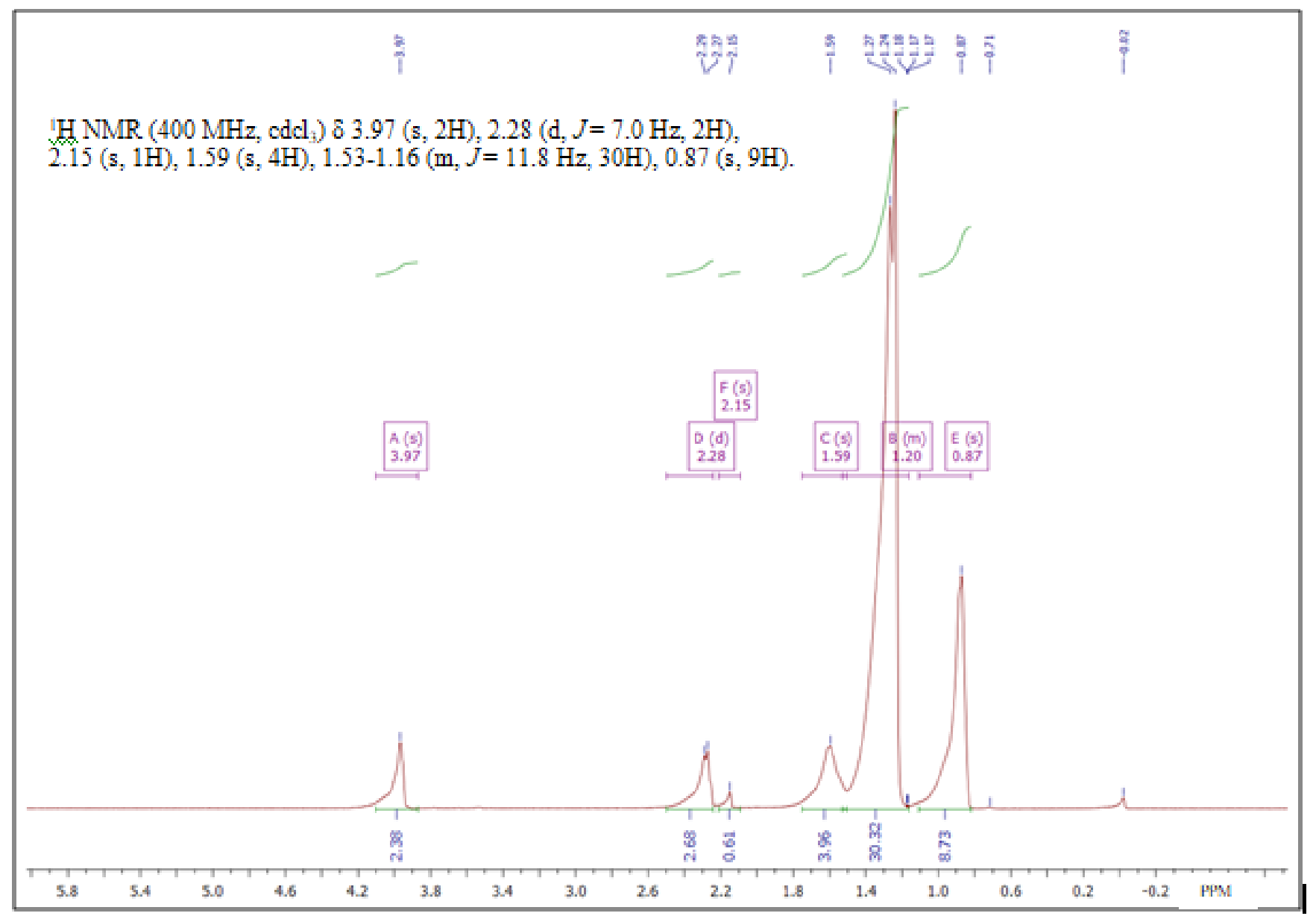

Figure 9. ${ }^{1} \mathrm{HNMR}$ analysis for the purified product from the enzymatic esterification of 2-ethylhexanol and palmitic acid. 


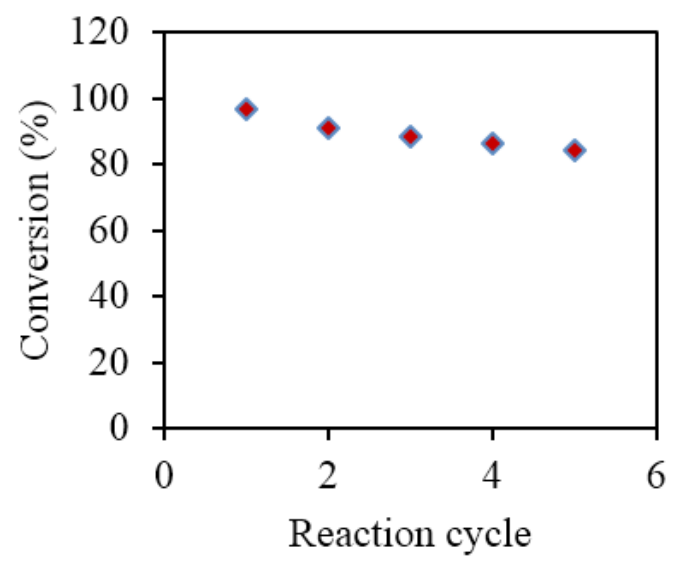

Figure 10. Reusability study [Reaction Conditions::palmitic acid: 2-ethylhexanol molar ratio, 1:5.5; enzyme loading, $5.61 \%(\mathrm{w} / \mathrm{w})$; ultrasound power-79.54, W duty cycle- $48.04 \%$, temperature, $60^{\circ} \mathrm{C}$; ultrasound frequency, $25 \mathrm{kHz}$ and $120 \mathrm{~min}$ reaction time].

decrease in conversion was due to excess exposure of ultrasound irradiation that may denature the enzyme (Gharat \& Rathod, 2013; Sinisterra et al, 1992). The feasibility of the enzyme-catalyzed reaction was determined by calculating the amount of desired product $(\mathrm{kg})$ per $\mathrm{kg}$ of immobilized enzyme at each cycle of reusability. Here we obtained $89 \mathrm{~kg}$ of 2-EHP per $\mathrm{kg}$ of the immobilized Fermase enzyme after 5 cycles of reusability. Tufvesson et al., (2011) reported a range of required productivity for different types of processes and products, based on typical values of biocatalyst and product cost. Although the value obtained is lower than reported for industrial feasibility, only 5 cycles are reported, which can be further continued up to 10-15 cycles, making the process industrially feasible. Considering the current scenario, enzyme catalysis is quite expensive in terms of process cost per $\mathrm{kg}$ of the enzyme, but considering the benefits of the enzymatic process it is far better in terms of environmental protection, minimization of process cost by reducing/ eliminating down streaming costing and the purity of the products. In the future, advancement in biotechnology and genetic studies may decrease the overall process cost and could be used as an effective catalyst.

\section{Surface morphology of immobilized lipase}

Figure 11 shows the images of the unused and ultrasound irradiated reused immobilized lipase after 5 cycles of reusability. From the figure, it is revealed that repeated use of enzyme in presence of ultrasound irradiation causes morphological changes. Figure 11(A) shows that untreated enzyme was kind of smooth; whereas the reused enzyme structure in Figure 11(B) exposes rough surface. This morphological change can be attributed to the successive ultrasound

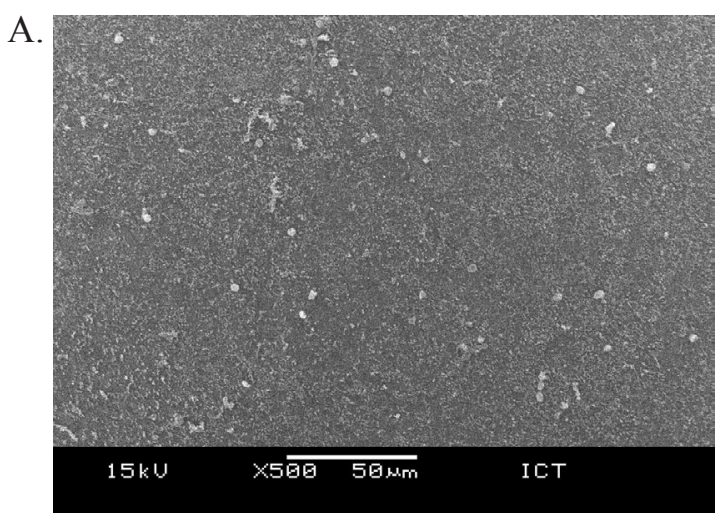

B.

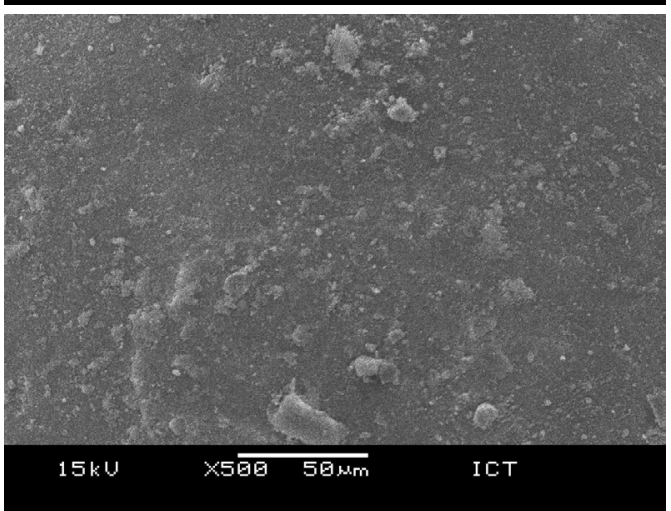

Figure 11. SEM images of: (A) unused immobilized lipase and (B): reused immobilized lipase.

irradiation. Similar kind of the surface morphology was observed by Subhedar and Gogate (2016) in the presence of ultrasound treatment for the immobilized Lipozyme TLIM lipase. The ultrasound usage affects the modification in the immobilized Fermase CALB 10000 enzyme with respect to morphological as well as at the molecular level. The repetitive use of enzyme with ultrasound causes the deactivation of the enzyme.

\section{CONCLUSION}

The ultrasound assisted synthesis of 2-ethylhexyl palmitate was successfully carried out with Fermase CALB 10000 as a biocatalyst. The optimization of the process was performed by RSM using central composite design in a solvent free condition. Four variables, namely, molar ratio, enzyme loading, ultrasound power and duty cycle, were appraised. The molar ratio, enzyme loading, and ultrasound power show a significant effect on the conversion, while duty cycle did not show a significant effect. The ANOVA analysis predicted the good fit of the model. The highest conversion $(96.56 \%)$ was achieved at 1:5.5 acid to alcohol molar ratio, $5.61 \%$ enzyme loading, $79.54 \mathrm{~W}$ ultrasound power and $48.04 \%$ duty cycle in shorter reaction time (120 $\mathrm{min})$. The RSM method gives a 2-3\% increase in conversion as compared to the one factor at a time method. The ultrasound energy improves the conversion of 2-ethylhexyl palmitate by reducing 
reaction time and enzyme amount when compared to conventional synthesis. Therefore, this study proves that ultrasound assisted enzymatic synthesis is a clean technology for the synthesis of 2-ethylhexyl esters due to cavitation phenomena, which enhance the mass transfer in a heterogeneous system and accelerate the conversion of ethylhexyl esters.

\section{REFERENCES}

Ajmal, M., Fieg, G., Keil, F. Analysis of process intensification in enzyme catalyzed reactions using ultrasound, Chemical Engineering and Processing: Process Intensification, 110, 106-113 (2016). https://doi.org/10.1016/j.cep.2016.10.002

Badgujar, K.C., Pai, P.A. Bhanage B.M., Enhanced biocatalytic activity of immobilized Pseudomonas cepacia lipase under sonicated condition, Bioprocess and Biosystems Engineering, 39, 211-221 (2016). https://doi.org/10.1007/s00449-015-1505-5

Bansode, S.R., Rathod, V.K. An Investigation of lipase catalysed sonochemical synthesis: A review, Ultrasonics - Sonochemistry, 38, 503-529 (2017). https://doi.org/10.1016/j.ultsonch.2017.02.028

Bezerra, M.A., Santelli, R.E., Oliveira, E.P., Villar, L.S., Escaleira, L. A. Response surface methodology (RSM) as a tool for optimization in analytical chemistry, Talanta, 76, 965-977 (2008). https://doi.org/10.1016/j.talanta.2008.05.019

Bucalá, V., Foresti, M.L., Trubiano, G., Ferreira, M.L., Briozzo, M., Bottini, S. Analysis of solvent-free ethyl oleate enzymatic synthesis at equilibrium conditions, Enzyme and Microbial Technology, 38, 914-920 (2006). https://doi.org/10.1016/j. enzmictec.2005.08.017

Chang, S.-W., Shaw, J.-F., Yang, K.-H., Shih, I.-L., Hsieh, C.-H., Shieh, C.-J. Optimal lipase-catalyzed formation of hexyl laurate, Green Chemistry, 7, 547-551 (2005). https://doi.org/10.1039/b501724f

De Souza, M.C.M., Dos Santos, K.P., Freire, R.M., Barreto, A.C.H., Fechine, P.B.A., Gonçalves, L.R.B. Production of flavor esters catalyzed by Lipase B from Candida antarctica immobilized on magnetic nanoparticles, Brazilian Journal of Chemical Engineering, 34, 681-690 (2017). https:// doi.org/10.1590/0104-6632.20170343s20150575

Deshmukh, A.R., Rathod, V.K. Intensification of enzyme catalysed synthesis of hexyl acetate using sonication, Green Processing and Synthesis, 6, 5562 (2017). https://doi.org/10.1515/gps-2015-0117

Gawas, S.D., Rathod, V.K. Enhancement in synthesis of ethyl laurate catalyzed by fermase by combined e ff ect of ultrasound and stage wise addition of ethanol, Chemical Engineering \& Processing: Process Intensification, 125, 207-213 (2018). https://doi.org/10.1016/j.cep.2017.12.018
Gharat, N., Rathod, V.K. Ultrasound assisted enzyme catalyzed transesterification of waste cooking oil with dimethyl carbonate., Ultrasonics Sonochemistry, 20, 900-5 (2013). https://doi. org/10.1016/j.ultsonch.2012.10.011

Gogate, P.R., Kabadi, A.M. A review of applications of cavitation in biochemical engineering/biotechnology, Biochemical Engineering Journal, 44, 60-72 (2009). https://doi.org/10.1016/j.bej.2008.10.006

He, X.L., Chen, B.Q., Tan, T.W. Enzymatic synthesis of 2-ethylhexyl esters of fatty acids by immobilized lipase from Candida sp. 99-125, Journal of Molecular Catalysis B: Enzymatic, 18, 333-339 (2002). https://doi.org/10.1016/S13811177(02)00114-5

Kapucu, N., Güvenç, F., MehmetoĞLU, Ü., Çalimli, A., Kapucu, H. Lipase catalyzed synthesis of oleyl oleate: Optimization by response surface methodology, Chemical Engineering Communications, 190, 779-796 (2003). https://doi. org/10.1080/00986440302107

Khan, N, Rathod, V.K. Enzyme catalyzed synthesis of cosmetic esters and its intensification: A review, Process Biochemistry, 50, 1793-1806 (2015). https://doi.org/10.1016/j.procbio.2015.07.014

Khan, N., Gawas, S.D., Rathod, V.K., Enzymecatalysed production of n-butyl palmitate using ultrasound-assisted esterification of palmitic acid in a solvent-free system, Bioprocess and Biosystems Engineering, 41, 1621-1634 (2018). https://doi. org/10.1007/s00449-018-1988-y

Khan, N., Jadhav, S., Rathod, V.K. Enzymatic synthesis of n-butyl palmitate in a solvent-free system: RSM optimization and kinetic studies, Biocatalysis and Biotransformation, 34, 99-109 (2016). https://doi. org/10.1080/10242422.2016.1212847

Kulkarni, V.M., Rathod, V.K. Mapping of an ultrasonic bath for ultrasound assisted extraction of mangiferin from Mangifera indica leaves, Ultrasonics Sonochemistry, 21, 606-611 (2014). https://doi.org/10.1016/j.ultsonch.2013.08.021

Martins, A.B., Schein, M.F., Friedrich, J.L.R., Fernandez-Lafuente, R., Ayub, M. A. Z., Rodrigues, R.C. Ultrasound-assisted butyl acetate synthesis catalyzed by Novozym 435: enhanced activity and operational stability., Ultrasonics Sonochemistry, 20, 1155-60 (2013). https://doi.org/10.1016/j. ultsonch.2013.01.018

Melo, L.L.M.M., Pastore, G.M., Macedo, G. A. Optimized synthesis of citronellyl flavour esters using free and immobilized lipase from Rhizopus sp., Process Biochemistry, 40, 3181-3185 (2005). https://doi.org/10.1016/j.procbio.2005.01.019

Richetti, A., Leite, S.G.F., Antunes, O. A. C., Lerin, L. A., Dallago, R.M., Emmerich, D. Assessment of process variables on 2-ethylhexyl palmitate 
production using Novozym 435 as catalyst in a solvent-free system, Bioprocess and Biosystems Engineering, 33, 331-337 (2010b). https://doi. org/10.1007/s00449-009-0328-7

Richetti, A., Leite, S.G.F., Antunes, O. A. C., De Souza, A.L.F., Lerin, L. A., Dallago, R.M. Optimization of 2-ethylhexyl palmitate production using lipozyme RM im as catalyst in a solvent-free system, Applied Biochemistry and Biotechnology, 160, 2498-2508 (2010a). https://doi.org/10.1007/s12010-0098756-z

Rokhina, E. V, Lens, P., Virkutyte, J. Low-frequency ultrasound in biotechnology: state of the art., Trends in Biotechnology, 27, 298-306 (2009). https://doi. org/10.1007/s12010-009-8756-Z

Sancheti, S. V., Gogate, P.R. A review of engineering aspects of intensification of chemical synthesis using ultrasound, Ultrasonics Sonochemistry, 36, 527-543 (2016). https://doi.org/10.1016/j. ultsonch.2016.08.009

Sinisterra, J. V. Application of ultrasound to biotechnology: an overview., Ultrasonics, 30, 180-185 (1992). https://doi.org/10.1016/0041624X(92)90070-3

Spinelli, D., Coppi, S., Basosi, R., Pogni, R. Biosynthesis of ethyl butyrate with immobilized Candida rugosa lipase onto modified Eupergit ${ }^{\circledR} C$,
Biocatalysis, 1, 1-12 (2014). https://doi. org/10.2478/boca-2014-0001

Subhedar, P.B., Gogate, P.R. Ultrasound assisted intensification of biodiesel production using enzymatic interesterification, Ultrasonics Sonochemistry, 29, 67-75 (2016). https://doi. org/10.1016/j.ultsonch.2015.09.006

Tan, T., Chen, B.Q., Ye, H. Enzymatic synthesis of 2-ethylhexyl palmitate by lipase immobilized on fabric membranes in the batch reactor, Biochemical Engineering Journal, 29, 41-45 (2006). https://doi. org/10.1016/j.bej.2005.02.033

Tufvesson, P., Lima-Ramos, J., Nordblad, M., Woodley, J. M. Guidelines and Cost Analysis for Catalyst Production in Biocatalytic Processes., Organic Process Research \& Development, 15, 266-274 (2011). https://doi.org/10.1021/op1002165

Waghmare, G. V., Rathod, V. K. Ultrasound assisted enzyme catalyzed hydrolysis of waste cooking oil under solvent free condition, Ultrasonics Sonochemistry, 32, 60-67 (2016). https://doi. org/10.1016/j.ultsonch.2016.01.033

Zhang, D.H., Zhang, J.Y., Che, W.C., Wang, Y. A new approach to synthesis of benzyl cinnamate: Optimization by response surface methodology, Food Chemistry, 206, 44-49 (2016). https://doi. org/10.1016/j.foodchem.2016.03.015 
